\title{
Article
}

\section{Implementing the PREP2 algorithm to predict upper limb recovery potential after stroke in clinical practice: a qualitative study}

Connell, Louise Anne, Chesworth, Brigit, Ackerley, Suzanne, Smith, Marie-Claire and Stinear, Cathy M.

Available at http://clok.uclan.ac.uk/36575/

Connell, Louise Anne ORCID: 0000-0002-0629-2919, Chesworth, Brigit ORCID: 0000-0001-7936-5536, Ackerley, Suzanne ORCID: 0000-0002-7059-3329, Smith, Marie-Claire and Stinear, Cathy M. (2021) Implementing the PREP2 algorithm to predict upper limb recovery potential after stroke in clinical practice: a qualitative study. Physical Therapy, 101 (5). ISSN 0031-9023

It is advisable to refer to the publisher's version if you intend to cite from the work. http://dx.doi.org/10.1093/pt/pzab040

For more information about UCLan's research in this area go to http://www.uclan.ac.uk/researchgroups/ and search for <name of research Group>.

For information about Research generally at UCLan please go to http://www.uclan.ac.uk/research/

All outputs in CLoK are protected by Intellectual Property Rights law, including Copyright law. Copyright, IPR and Moral Rights for the works on this site are retained by the individual authors and/or other copyright owners. Terms and conditions for use of this material are defined in the policies page. 
TITLE: Implementing the PREP2 algorithm to predict upper limb recovery potential after stroke in clinical practice: a qualitative study

RUNNING HEAD: Implementing PREP2 in clinical practice

TOC SECTION/CATEGORY: Implementation Science

ARTICLE TYPE: Original Research, Qualitative

AUTHORS:

Louise A. Connell, ${ }^{1,2}$ Brigit Chesworth, ${ }^{1}$ Suzanne Ackerley, ${ }^{3}$ Marie-Claire Smith, ${ }^{3,4}$ Cathy M. Stinear ${ }^{3}$

\section{AUTHOR INFORMATION:}

1. Faculty of Health \& Wellbeing, University of Central Lancashire, Preston, Lancashire, United Kingdom PR1 2HE. Address all correspondence to Prof Connell at:

laconnell@uclan.ac.uk.

2. East Lancashire Hospitals NHS Trust, Haslingden Road, Blackburn, United Kingdom BB2 $3 \mathrm{HH}$

3. Department of Medicine, University of Auckland, Private Bag 92019, Auckland 1142, New Zealand

4. Allied Health, Auckland District Health Board, 2 Park Rd, Grafton, Auckland 1023, New Zealand 


\section{ABSTRACT}

\section{Word count $=$ Revised 277}

\section{Background}

$5 \quad$ Predicting motor recovery after stroke is a key factor when planning and providing

6 rehabilitation for individual patients. The PREP2 algorithm has been developed to help

7 clinicians predict upper limb functional outcome. Translating evidence-based interventions

8 into clinical practice can be challenging and slow. However, shortly after its external local

9 validation, PREP2 was successfully implemented into clinical practice at the same site in

10 New Zealand. In parallel to further model validation, useful lessons can be learned from this

11 experience to aid future implementation.

13 Objective

14 To explore how PREP2 was implemented in clinical practice within the Auckland District 15 Health Board (ADHB) in New Zealand.

17 Design

18 A case study design using semi-structured interviews.

\section{Methods}

21 Nineteen interviews were conducted with clinicians involved in stroke care at ADHB. To

22 explore factors influencing implementation, interview content was coded and analysed using the Consolidated Framework for Implementation Research. Strategies identified by 
24 the Expert Recommendations for Implementing Change (ERIC) project were used to

25 describe how implementation was undertaken.

26

27 Results

28 Implementation of PREP2 was initiated and driven by therapists. Key factors driving

29 implementation were the support given to staff from the implementation team; the

30 knowledge, beliefs and self-efficacy of staff, and the perceived benefits of having PREP2

31 prediction information. Twenty-six ERIC strategies were identified relating to three areas:

32 the implementation team, the clinical/academic partnerships and the training.

34 Limitations

35 Limitations included potential self-selection bias, reliance on clinicians' ability to recall

36 events, and potential social desirability bias affecting interview content.

\section{Conclusions}

39 The PREP2 prediction tool was successfully implemented in clinical practice at ADHB.

40 Barriers and facilitators to implementation success have been identified, and

41 implementation strategies described. Lessons learned can aid future development and

42 implementation of prediction models in clinical practice.

43

44

45 
47 Predicting recovery potential for individual patients after stroke is difficult but important for 48 planning rehabilitation, setting realistic treatment goals and managing patient expectations.

49 Competing priorities for rehabilitation mean time available for upper limb (UL) therapy is

50 often very limited, with an average of four minutes spent on arm-related activity during treatment sessions. ${ }^{1}$ This means UL therapy needs to be targeted and individualised to achieve the greatest gains in a short timeframe.

Current practice for making predictions for UL recovery after stroke is a 'wait-and-see' approach. Clinicians often find it difficult to accurately predict functional outcomes. Studies suggest therapists are accurate in approximately $50-60 \%$ of patients, which is little better than chance. ${ }^{2,3}$ Currently, no single clinical measure or neurological biomarker accurately predicts motor recovery or outcome for all patients. There is also presently no consensus on the use of predictive models of stroke motor recovery, though it is generally agreed that any model will need to clearly demonstrate clinical feasibility and external validity

61 before implementation in routine clinical practice. ${ }^{4,5}$ One of the most important clinical predictors for UL recovery is severity of initial motor impairment. ${ }^{6}$ However, around half of patients with severe initial impairment achieve good UL function within the first 3 months post-stroke. ${ }^{7}$ This is because they have a functionally intact corticospinal tract that is not apparent on clinical assessment, but is detectable with transcranial magnetic stimulation

66 (TMS). Incorrectly assuming poor UL recovery potential in patients with severe motor

67 impairment early after stroke may affect patient goal setting and selection of rehabilitation strategies, leading to failure to realise actual recovery potential. 
70 The Predict Recovery Potential (PREP2) algorithm ${ }^{8}$ (Figure 1) sequentially combines clinical

71 assessment and TMS testing in the first week following stroke to predict UL functional

72 outcomes at 3 months post-stroke. A detailed description of the PREP2 algorithm is

73 provided online. ${ }^{9}$ In brief, the PREP2 algorithm starts with evaluating paretic UL strength by

74 obtaining a shoulder abduction and finger extension (SAFE) score, using Medical Research

75 Council (MRC) grading. If the SAFE score on day 3 post-stroke is 5 or more, patients are expected to have an Excellent or Good UL functional outcome within 3 months, depending on their age ( $<$ or $\geq 80$ y). If a patient's day 3 SAFE score is less than $5, T M S$ is used to evaluate corticospinal tract function. If a motor-evoked potential is elicited (MEP+) in the extensor carpis radialis or first dorsal interosseous muscles of the paretic $\mathrm{UL}$, the patient is expected to achieve a Good UL functional outcome. Patients without MEPs (MEP-) are expected to achieve a Limited or Poor UL functional outcome by 3 months, depending on their overall stroke severity measured with the National Institute of Health Stroke Scale (NIHSS).

84

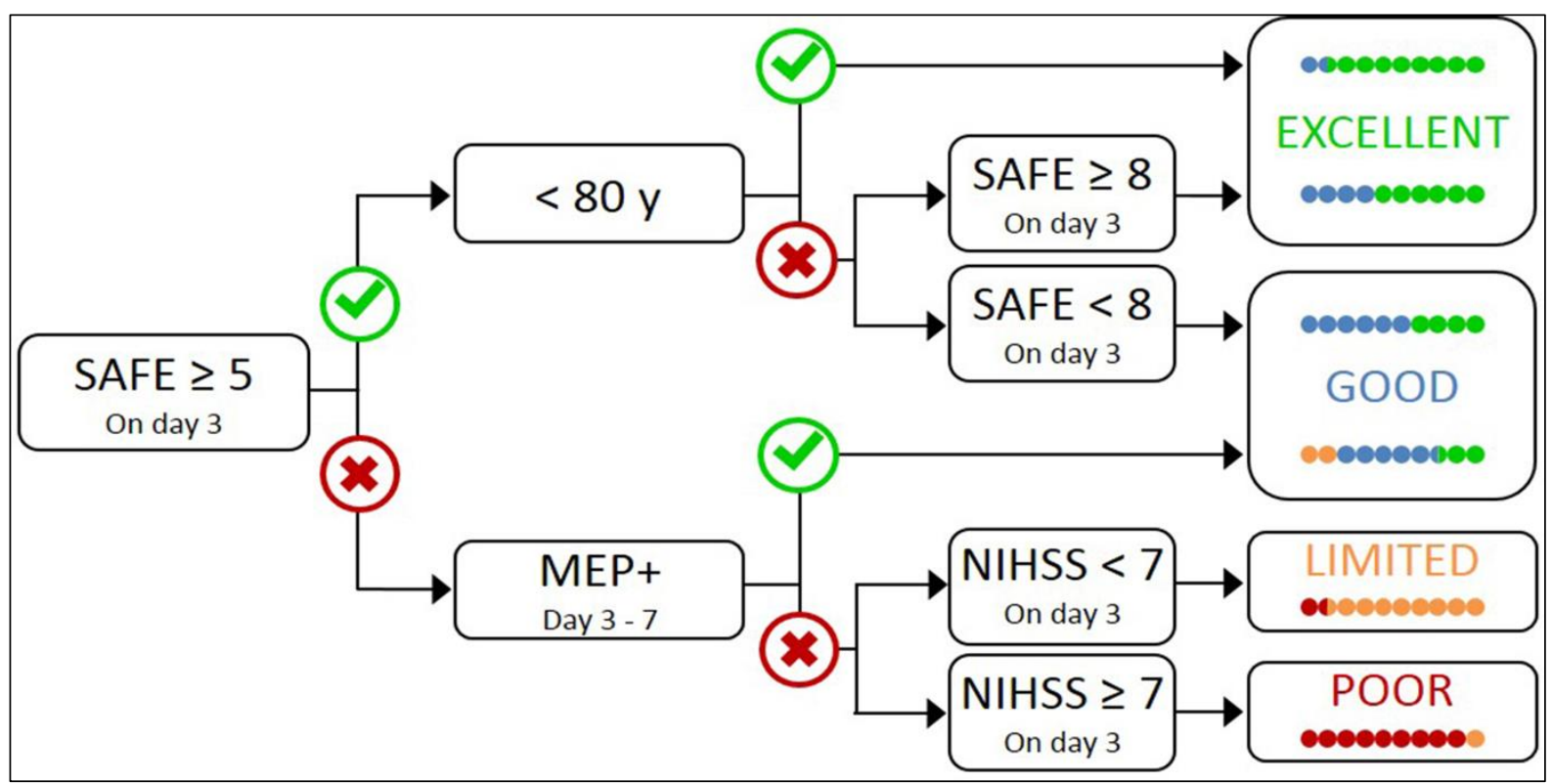



evaluating prior to promoting widespread implementation of PREP2.

Figure 1: The PREP2 Algorithm ${ }^{8}$

The PREP2 prediction categories are: ${ }^{8}$ to be affected by weakness, slowness and clumsiness. grasp function and be able to use in some bilateral activities. hand and arm. the algorithm and highlighting the importance of considering the dynamic interplay between the intervention and implementation early in development. algorithm has not yet been externally validated at a different site or in a different

- Excellent: Expected to be able to use the hand and arm in usual daily activities.

- Good: Expected to be able to use the hand and arm in usual daily activities but likely

- Limited: Expected to have limited use of the hand and arm but may have some gross

- Poor: Expected to have limited return of movement without functional use of the

PREP was developed ${ }^{10}(n=50)$, then refined to PREP2 ( $n=157+$ original 50$)^{8}$ in Auckland, New Zealand. PREP2 was refined by removing the need for MRI, improving the clinical utility of

PREP2 makes correct predictions for $75 \%$ of patients. The majority of positive and negative predictive values for different PREP2 categories were over $80 \%$. fanged between $83 \%$ and 99\%.However, there is still scope for further improvement in the predictive accuracy of the algorithm, especially within the Good category. However, it Additionally, the PREP2 healthcare system. PREP2 refinement and validation work is therefore on-going and needs 108 
In parallel to further validation it is important to explore clinical utility, as developing an

110 unusable model is of little value. The MRC guidance for stratified medicine recognizes that

111 "the ability of the stratified medicine approach to change clinical practice and positively

112 impact on human health depends not only on the methodological rigour ... but also on

113 effective engagement and communication with the wider stakeholders involved." ${ }^{11}$. A major

114 challenge in healthcare is translating research advances into changes in healthcare delivery.

115 Typically there is a 17-year lag between scientific evidence reporting and clinical

116 implementation ${ }^{12}$, which delays access to potential benefits for patients and clinicians.

117 Unusually, the PREP2 algorithm was implemented into routine clinical care at the Auckland

118 District Health Board (ADHB) within 18 months of external-validation at this site. The

119 Prognosis Research Strategy (PROGRESS) group have highlighted the need for more research

120 into understanding what impedes, and what accelerates, appropriate translation of

121 evidence to use of prognostic models. ${ }^{13}$. We aim to use implementation frameworks to

122 capitalise on this unique opportunity to explore clinically driven, 'natural' implementation of

123 a new prediction tool, to describe the process and learn lessons for future implementation.

126 Purpose

128 To explore how PREP2 was implemented into clinical practice within ADHB in New Zealand.

\section{Objectives}


133 1. To explore factors influencing implementation of PREP2, as perceived by staff.

1342 2. To identify the implementation and training strategies used to implement PREP2 into $135 \quad$ clinical practice.

138 Methods

\section{Study Design}

141 A case study approach was used with data collected via semi-structured interviews. The

142 theoretical frameworks underpinning the study design were the Normalization Process

143 Theory and Consolidated Framework for Implementation Research (CFIR). Normalization

144 Process Theory can be used to understand the dynamic processes involved in enabling new

145 interventions to become embedded in routine practice ${ }^{14}$. The CFIR provides a menu of

146 constructs that have been associated with effective implementation ${ }^{15}$ and includes the

147 domains: inner setting (e.g. stroke service settings); characteristics of the individuals (e.g.

148 clinicians); intervention characteristics (e.g. PREP2); and outer setting (e.g. patient and

149 external factors). In addition, the refined compilation of implementation strategies from the

150 Expert Recommendations for Implementing Change (ERIC) project ${ }^{16}$ was used to describe

151 implementation strategies. 
153 The Standards for Reporting Qualitative Research: A Synthesis of Recommendations ${ }^{17}$ was

154 used.

155

156

157 Setting

158 ADHB, New Zealand.

159

160

161 Participant Selection

162 Clinicians involved in stroke care at ADHB were invited to participate and were provided

163 with participant information sheets via clinical leaders in allied health, nursing and medical

164 services. Interested clinicians contacted the research team by email or phone. After

165 providing written informed consent, participants were interviewed outside of their working

166 hours. They each received a $\$ 50$ voucher as a koha (gift) to acknowledge their participation.

167

168 
170 The Normalization Process Theory and the CFIR were used in the development of the

171 interview guide for the study (Appendix 1), based on previous literature. ${ }^{18,19}$ The interview

172 guide was reviewed and piloted by clinical therapists.

173

174 The interviews were conducted by the lead author (LC). Participants were not known to the

175 interviewer. Participants were aware that the interviewer was not part of the PREP2 research team or implementation team and wanted an honest perspective to learn lessons

177 for implementation, and that criticisms were welcomed. Interviews were digitally recorded and transcribed verbatim to enable in-depth analysis.

\section{Researcher Characteristics and Reflexivity}

183 The researchers held a pragmatist worldview, basing the inquiry on the assumption that collecting diverse types of data provides a more complete understanding of a research problem. The interviewer is a clinician-scientist, both an experienced researcher and Physical Therapist in stroke rehabilitation. Hence, she was aware of a number of potential issues which may influence how PREP2 is implemented. To reduce any associated bias, two

188 further researchers were involved in the analysis and interpretation of the data. These two researchers have clinical backgrounds in Medicine $(\mathrm{BC})$ and Physical Therapy (SA) and are experienced in health research. 
Data Analysis

194

195 Interview transcripts were imported into NVivo 12 for analysis. The CFIR was used to code

196 data, with additional free codes developed where needed. To establish a shared

197 understanding and interpretation of the coding framework, all three researchers started by

198 coding the same two transcripts. The coded transcripts were compared and any variance in

199 interpretation of data and application of codes was discussed to arrive at a mutual decision.

200 Subsequently the remaining transcripts were coded separately by two researchers

201 independently. Excerpts used were identified by participant number only.

202

203

204

\section{Member checking}

205

206 Key themes identified during data analysis were synthesized and depicted as four

207 infographics, one for each CFIR domain (see Supplementary file). The infographics and table

208 summarising implementation strategies used (Table 1) were sent to participants for

209 feedback.

210

211 


\section{Results}

213

214 Nineteen interviews were conducted across the hyperacute, acute, rehabilitation and

215 community stroke services in May 2019.

216

217 Participants were Physical Therapists (PTs) (n=8); Occupational Therapists (OTs) $(n=4)$,

218 Nurses $(n=2)$, Medical Doctors ( $n=2)$, Rehabilitation Assistants $(n=2)$ and a Speech and

219 Language Therapist $(n=1)$. Their experience within neurology varied from less than one to

220 over 20 years' experience.

221

222 Data collection ended upon achieving data saturation, which was agreed through ongoing

223 analysis by three researchers.

224 Factors Influencing Implementation of PREP2

225 Factors are presented according to their CFIR domains, together with supporting quotes.

226 Table 2 summarises these results.

227

228

229

Inner Setting

230 
233 All participants agreed that PREP2 is now embedded in routine clinical care, advancing from

234 research to practice. Implementation was phased: starting with patients with a SAFE score

235 of 5 or more and delivering Excellent and Good predictions, and later adding TMS testing

236 and NIHSS score for patients with a SAFE score of less than 5 and delivering all 4 predictions.

237 PREP2 has become integrated within standard orientation for new staff.

P04: "it's just another thing to do and it's become the norm"

244 Readiness for Implementation

245 At an organisational level, there was approval and buy-in from management staff.

246 Leadership engagement was recognized as an important source of support, but

247 implementation was led by the Physical Therapy team.

248 P02: "obviously getting clearance from a management perspective... we were really well

249 supported"

250 P10: "it's sort of run by a [PT] really and they understand it ... do it themselves, really lead it 251 and then liaise with the medical team" 
252 Implementation evolved over time, with OTs involved at a later stage. There was recognition

253 that this could have been earlier.

254 P17: "the inclusion of occupational therapy in the PREP2 project was never really a thing, 255 maybe it's because it was developed by a [PT] and ... it started off there but I feel like OT 256 probably missed the boat a little bit"

259 The timing of PREP2 assessments over the first week post-stroke meant the involvement of

260 different wards (acute and rehabilitation) and different staff to obtain and deliver PREP2

261 predictions. These logistical factors meant sufficient staffing was required across services to 262 enable completion of tests.

263 P15: "You need people ... both from acute and rehab... it's harder for the rehab people to be 264 doing the TMS when the patient is still in the acute setting"

Networks and Communication

267 Communication was recognized as important to enable tests to be completed on time and

268 ensure consistent language regarding the delivery of prediction information. This had positive spill-over effects on general communication within the multi-disciplinary team. 
P19: "When everyone uses the same terminology and gives the patient the same

272 information, it's easy for them to process because they're not getting conflicting ideas"

P04: "with the aphasic patients and delivering upper limb predictions to them, it does involve

275 a collaborative effort and getting the right people involved so having discussions with speech

276 and language therapists"

277

278 Communication between staff was generally good within a service, although shift patterns

279 of nursing staff were recognized as challenging. Communication was more difficult when

280 patients moved across services, such as transferring to the rehabilitation ward or the

281 community.

282 P04: "I'm on the hyperacute and acute stroke unit so once patients have been accepted to

283 rehab they go up pretty quickly... I'm sure there's things been lost in translation when people

284 move"

285

286 P03: "they'd come up to the wards sometimes we'll ask them ... 'what have you been told

287 about your recovery of your upper limb?' and they'll be like 'nothing'. You don't know

288 whether they don't remember or whether they chose not to take it in"

289

Implementation climate 
291 Generally, the organisation was supportive towards training and staff development, with

292 the PREP2 implementation team delivering training that staff were encouraged to attend.

293

294 P03:" they do such good training and they do ... keep us really well informed"

296 P14: "we don't really have to justify attending [training], ...the autonomy is on you, the onus

297 is on you to attend ... you're encouraged to prioritise it"

298

299 There was recognition that there was no feedback loop to learn from patients, with no

300 insight regarding prediction validity.

301

302 P05: "it's probably one of the gaps in our stroke service ... we don't actually follow up stroke

303 patients in clinic... there's no other mechanism that we really get any feedback"

304

305

306

\section{Characteristics of the Individuals}

307

$308 \quad$ Knowledge and Beliefs

309 
310 Most staff held positive perceptions regarding PREP2 as a tool to predict UL functional

311 outcome and could articulate detailed patient stories that seemed influential in shaping

312 those beliefs.

313

314 P02: “... PREP ... that's awesome, useful, meaningful, something that we can actually use on

315 a daily basis, something that gives us information that we really want in the first few days or

316 weeks after a patient's stroke, something that gives us a bit of direction, gives us confidence

317 that we're ... going down the right track with a patient, that we're ... working towards things

318 that are actually realistically achievable for them or things that are actually the best use of

319 their energy and time"

320

321 P04: "this is relevant, this is evidence, this is a way to give people a realistic prediction of

322 their upper limb recovery which is exactly what we've been searching for, for years."

323

324

325 Self-Efficacy

326

327 It was acknowledged that staff are trained to different levels depending on their needs.

328 Most PTs and OTs are trained to complete the clinical assessments (SAFE score, NIHSS) and

329 deliver Excellent and Good predictions, with fewer people trained to have expertise in TMS

330 and deliver Limited and Poor predictions.

331 
P05: "the poor prediction or the good prediction if they've got MEPS, that's done by the TMS

333 team and I don't think I personally would be at the point yet, with enough experience to up-

334 skill to do that"

335

336 Therapists had differing levels of understanding in the multiple aspects of PREP2, with

337 variable confidence and recognition that building confidence took time.

338

P01: "so it was ... kind of, these are great but I don't really understand how to use them... I

340 struggled for a long time for the language that I used when I spoke to patients about

341 translating that kind of prediction into rehab"

342

343 P02: "I'm extremely confident with using PREP...it's ... gone through a spectrum of being not

344 confident at all to use PREP even in clinical practice to being confident to use it myself to

345 being confident to teach it to other people to be confident to support it in to

346 implementation, confident to teach it as a service"

Other Personal Attributes

Passionate and knowledgeable therapists gave the wider team support and confidence and 'champion' as an advocate. 
P15: "you need a really strong and passionate core team who are promoting it. Because I

356 think we definitely did here, like one of the girls who was heavily involved in it ... she does

357 talk about it a lot but ... she's so passionate about it and so no one can ... forget about it or

358 let it slip ... because she's like a big driver for it"

359

360 P16: "having a champion... somebody that they are able to contact in case they would like to

361 ask questions"

362

363 Therapists also appreciated the opportunity to be involved in 'ground-breaking practice' and

364 to learn new skills that advance PT and OT professions, although this opportunity was also

365 felt to be a bit daunting.

366

367 P17: "it's completely brand new to all of us, like it's almost an entirely new scope for [PTs]

368 here... which is really exciting"

369

370 P04: "but it is quite a bit of pressure... it is quite a step up in terms of what we are doing in

371 clinical practice and you are delivering quite significant information to a patient and it does

372 come with a bit of responsibility"

373 Intervention Characteristics

374

375 Complexity 
The PREP2 algorithm includes relatively 'simple' biomarkers but there are still complexities

378 when implementing it in a clinical setting.

380 Understanding who, and how many staff, need to be trained for the different aspects of 381 PREP2 to ensure sustainability was identified as an important and ongoing issue. This was

382 challenging due to high staff turn-over caused by staff absence, rotation, leave or 383 resignation.

384

P15: "just making sure that you have a really good mix of people across the wards ...people trained in different things... so you could have a core team that can do the whole thing but I think it's really important to have lots of people who can help and do aspects of it"

The time cost of PREP2 was challenging, both in terms of undertaking the training required

390 and completing the assessments. Interestingly, the cost of the TMS machine was not

391 identified as a significant factor, possibly because the site already had access to one. within my clinical hours" because I'd rather have been doing the treatment" 
Evidence strength and quality

399

400 Having underpinning evidence for PREP2 increased staff confidence in using its predictions

401 and in general beliefs that the predictions were accurate, and when wrong they were "not

402 wrong by much" (P17). Practical experience of using PREP2 was also influential.

403

404 P10: "actually seeing the studies and seeing actual data on the predictive accuracy of it ...

405 that's quite useful"

406

407

408 Relative advantage

409

410 Overall clinicians found PREP2 predictions were useful for guiding and focusing UL

411 rehabilitation, although a few reported it had little influence on their treatment choices.

412

413 P04: "it just gave me hope and confidence to keep pushing and keep advocating and

414 knowing that this person does have the potential"

415 P19: "they get the same amount of therapy it's just the focus of the therapy, so someone

416 that has a good or an excellent, we're really focussing on re-learning how to use that hand

417 and doing everything with that hand trying to get the good one out of the way to really

418 focus. Whereas if someone's got the poor, you're focussing pretty much the same amount of

419 therapy time but on compensation rather than promoting use, and so it just means that 
420 you're getting better quality - well not better quality because the quality is the same but

421 you're getting what the patient needs sooner rather than trying to mix both"

422

P14: "the good [prediction] doesn't have that much effect on my practice ... because I do my

normal upper limb therapy"

425

Staff felt there was a benefit of reducing uncertainty for the patient around prognosis and giving better information to the patients. It enabled patients to deal with bad news of a poor outcome sooner, and careful consideration and support are given when delivering a poor prediction.

P05: "it's hard when people ask you questions and you're always saying 'I don't know, we'll have to see how you go' so it's nice to have something that you can kind of reference... I think it helps with that acceptance earlier on so for example if you get the poor prediction, in a way it's nicer, like they can start to ... accept that" psychology [a clinical psychologist] involved with a lot of patients so they can talk about the change to the future."

439 There were additional benefits in terms of better monitoring of patients, identifying

440 deterioration sooner.

442 P04: "it ... builds on our confidence in terms of noticing change, and especially with the SAFE 443 score because it is a really good way to monitor for those evolving infarcts" 
445 Some difficulties were posed when a prediction wasn't borne out in practice as quickly as

446 expected.

447

448 P01: "it's harder when people take longer to achieve their predictions because it's hard to stay positive for that person when they're not seeing the outcomes that they are hoping for."

450

451

452 Outer Setting

453

454 Patient needs and resources

455 There was recognition that patients (and their families) differ in terms of whether they want 456 a prediction or not.

457

458

P05: "they've only had a couple who haven't wanted to know, like most people want to

459 know."

460

461 It was also recognized that prediction information could affect a patient's mood and/or

462 motivation, either positively or negatively, and that having support available was helpful.

463 P12: "they may or may not be able to take it well, but ... they just need time and help, some support trying to go through the process and eventually people will accept it." P08: "it can motivate a lot of people in that uncertain or worried time" 
470 Implementation strategies evolved and were developed through trial and error rather than

471 being theoretically-driven. Initially it was thought that the main barrier to implementation

472 would be the use of TMS and so a "TMS team" was formed. The group worked as a

473 collective and had no nominated leader. Over time, this group self-identified as the

474 "Implementation team" and their focus evolved to ensure training for all aspects of PREP2,

475 with a recognition that sustainability was key, and that wider staff involvement was needed.

476 Later, a 'PREP2 lead therapist' role was created which ring-fenced time for implementation

477 of PREP2. The therapy team and academic team had a close relationship, with some staff

478 having joint roles.

479

480 Table 1 details the ERIC implementation strategies used, together with lessons learned for 481 future implementation efforts. 
484 The example of PREP2 implementation at ADHB demonstrates a practice change that was

485 initiated and driven by therapists. This study used the CFIR for analysis as a determinant

486 framework to link CFIR constructs to the success of the PREP2 implementation. The CFIR

487 domains identified as influential were the inner setting, the characteristics of the staff and aspects of the intervention itself. Specifically, the support given to staff from the

489 implementation team; the knowledge, beliefs and self-efficacy of staff; and the perceived benefits of having PREP2 prediction information, supported the implementation. This has parallels with what others have found. For example, a review regarding implementation in occupational therapy found the inner setting to be the most commonly identified determinant, ${ }^{20}$ and knowledge and beliefs of therapists have previously been shown to be

494 influential. ${ }^{18,21,22}$ What is yet to be understood, is how modifiable these factors are, if at all, and which implementation strategies are best placed to align to them.

497 The ERIC implementation strategies were used to retrospectively describe the

498 implementation undertaken by ADHB staff. We observed the use of 26 of the 73 ERIC

499 implementation strategies, which is a similar number to that detailed in other studies. ${ }^{23,24}$

500 The ERIC strategies used comprised three areas: the implementation team, the

501 clinical/academic partnerships and the training. Based upon the factors identified to

502 influence implementation of PREP2, and the implementation strategies observed, we have 503 provided guidance to aid future implementation efforts of prediction models. This offers

504 lessons learned based on practical experience, detailed using a systematic approach. There 
are published approaches to identifying determinants and matching strategies to address

506 them. ${ }^{25-27}$ It has also been argued that implementation strategies should be considered $a$

507 priori, ${ }^{28}$ with prospective planning to optimise the likelihood of implementation success, and

508 take account of complexity across different domains. ${ }^{29}$ This remains uncommon in clinical

509 practice and was not the case here. The implementation evolved over time, and

510 undoubtedly took a 'convoluted' journey, although ultimately implementation happened

511 and has been sustained. The individuals driving implementation were key: even if they made

512 mistakes and faced setbacks, they persevered and resolved issues. It is unknown whether

513 the implementation could have happened more quickly if fewer detours had occurred due

514 to implementation strategies having been identified prospectively. Methods such as the

515 CFIR-ERIC matching tool, which aims to address which ERIC implementation strategies

516 would best address specific CFIR-based contextual barriers, could be useful. ${ }^{30}$ Although

517 PREP2 is not yet ready for widespread implementation, Qour approach identified

518 retrospectively what worked well at ADHB and provided lessons learned to support future

519 implementation efforts of prediction models in research and ultimately in clinical practice. It

520 is a challenge to develop models that are both robust and clinically useable. Guidance such

521 as that offered by the PROBAST tool ${ }^{31}$, provides a structured way to assess the risk of bias of

522 studies on prediction models, and to assess their applicability for the targeted context and

523 population. However, using this tool would have resulted in PREP2 being considered as

524 having high concern of applicability due to the nature of measures used (namely the TMS component). Our in-depth study of implementation found that TMS was successfully used

526 with patients within one week post-stroke, highlighting the need to acknowledge all the

527 factors that influence implementation, not just the aspects of the intervention itself. 
530 Using both the CFIR constructs and ERIC categories provided a useful method for ensuring a

531 comprehensive inquiry of the implementation process and factors influencing it. Consistent

532 use of frameworks and theories should help contribute to knowledge about what works,

533 where, and why. There were some challenges with overlaps between domains of the CFIR

534 and the implementation strategies, with this inter-connectedness noted previously and felt

535 to be a necessity. ${ }^{23}$

536

\section{Limitations}

538 Participants in this study were invited volunteers, thus introducing a self-selection bias where staff with stronger opinions may be overrepresented. More rigorous and resource-

540 intensive methods of reporting implementation strategies have been reported, such as one

541 study ${ }^{32}$ in which implementation meetings in six sites over a five-month period were

542 observed, recorded and transcribed. However, this was not feasible when investigating

543 clinically-driven implementation retrospectively. The data collected in this study relied on

544 the healthcare professionals' ability to recall events from a few weeks to years prior to the

545 interviews which may affect data accuracy. Further, as the data is self-report in nature there

546 is the risk of a social desirability bias. However, prior to, and during the interviews it was

547 highlighted to participants that the interviewer was independent to the PREP2 team, the

548 data collected would be anonymised and that it would not be possible for them to be

549 identified, in the hope that they would be as candid as possible. 
553

554 Despite the well-established challenges and time lags associated with the implementation of

555 evidence-based interventions into clinical practice, the PREP2 intervention was successfully

556 implemented. The CFIR was used to explore the factors influencing this implementation

557 success, and we identified which implementation strategies were used. Key individuals were

558 influential in driving forward implementation and characteristics of the clinical setting,

559 together with the perceived advantage of the PREP2, contributed to implementation

560 success. Future teams hoping to validate and implement prediction tools in clinical practice

561 could build on the lessons learned and prospectively consider how these fit to their local

562 context.

563

564 


\section{Author Contributions and Acknowledgments}

566 Concept/idea/research design: L. Connell, MC Smith, C Stinear

567 Writing: L. Connell, B Chesworth, S Ackerley

568 Data collection: L. Connell

569 Data analysis: L. Connell, B Chesworth, S Ackerley

570 Project management: L. Connell

571 Fund procurement: L Connell, C Stinear

572 Providing participants: C Stinear

573 Consultation (including review of manuscript before submitting): MC Smith, C Stinear

574

575

576 The authors acknowledge the staff that gave up their time to take part in this study and

577 provide candid accounts of their experiences of PREP2. We also wish to thank Daniel

578 Osmond for his assistance with the transcriptions.

579

580

$581 \quad$ Ethical approval

582 This study was approved by the relevant university research ethics boards (UCLan STEMH

$5831000 \& 00078$ AHREC).

584

585 
586 Funding

587 The study was supported by a Dowager Countess Eleanor Peel Trust travel fellowship

588 awarded to L Connell, award number 4318. A grant to C Stinear from the Julius Brendel

589 Trust, HRC 11/270, assisted in funding research time for analysis.

590

591 The funders played no role in the conduct of the study.

592

593

594 Disclosures

595 The authors each completed the ICJME Form for Disclosure of Potential Conflicts of Interest.

596 Conflict of Interest: none declared.

597 


\section{References}

1. Hayward KS BS. Dose of arm activity training during acute and subacute rehabilitation post stroke: a systematic review of the literature. Clinical Rehabilitation. 2015;29(12):1234-1243.

2. Kwakkel G vDG, Wagenaar RC. Accuracy of physical and occupational therapists' early predictions of recovery after severe middle cerebral artery stroke. Clinical Rehabilitation. 2000;14:28-41.

3. Nijland RH vWE, Harmeling-van der Wel BC, Kwakkel G. Early Prediction of Functional Outcome After Stroke Investigators. Accuracy of physical therapists' early predictions of upper-limb function in hospital stroke units: the EPOS Study. Physical Therapy. 2013;93:460-469.

4. Rosso C, Lamy JC. Prediction of motor recovery after stroke: being pragmatic or innovative? Curr Opin Neurol. Aug 2020;33(4):482-487. doi:10.1097/WCO.0000000000000843

5. Stinear CM, Smith MC, Byblow WD. Prediction Tools for Stroke Rehabilitation. Stroke. Nov 2019;50(11):3314-3322. doi:10.1161/STROKEAHA.119.025696

6. Coupar F PA, Rowe P, Weir C, Langhorne P. Predictors of upper limb recovery after stroke: a systematic review and meta-analysis. Clinical Rehabilitation. 2012;26:291-313. 7. Nijland RH vWE, Harmeling-van der Wel BC, Kwakkel G; EPOS Investigators. Presence of finger extension and shoulder abduction within 72 hours after stroke predicts functional recovery: early prediction of functional outcome after stroke: the EPOS cohort study. Stroke. 2010;41(4):745-50.

8. $\quad$ Stinear CM BW, Ackerley SJ, Smith MC, Borges VM, Barber PA. PREP2: A biomarker-based algorithm for predicting upper limb function after stroke. Annals of Clinical and Translational Neurology. 2017;4(11):811-820.

9. Awad LN, Kesar TM, Reisman D, Binder-Macleod SA. Effects of repeated treadmill testing and electrical stimulation on post-stroke gait kinematics. Gait and Posture.

2013;37(1):67-71. doi:10.1016/j.gaitpost.2012.06.001

10. Stinear CM BP, Petoe M, Anwar S, Byblow WD. The PREP algorithm predicts potential for upper limb recovery after stroke. Brain. 2012;135(8):2527-35.

11. Medical Research Council. The MRC Framework for the Development, Design and Analysis of Stratified Medicine Research. 2018. https://mrc.ukri.org/publications/browse/mrcframework-for-stratified-medicine/

12. Morris ZS WS, Grant J. The answer is 17 years, what is the question: understanding time lags in translational research. Journal of the Royal Society of Medicine. 2011;104(12):510-520.

13. Hemingway H, Croft P, Perel P, et al. Prognosis research strategy (PROGRESS) 1: a framework for researching clinical outcomes. BMJ. Feb 2013;346:e5595.

doi:10.1136/bmj.e5595

14. May C FT. Implementing, embedding and integrating practices: an outline of Normalization Process Theory. Sociology. 2009;43(3):535-554

15. Damschroder LJ AD, Keith RE, Kirsh SR, Alexander JA, Lowery JC. Fostering implementation of health services research findings into practice: a consolidated framework for advancing implementation science. Implementation Science. 2009;4:50. 
16. Powell BJ WT, Chinman MJ, Damschroder LJ, Smith JL, Matthieu MM, Proctor EK, Kirchner JE. A refined compilation of implementation strategies: results from the Expert Recommendations for Implementing Change (ERIC) project. Implementation Science. 2015;10:21.

17. O'Brien BC HI, Beckman TJ, Reed DA, Cook DA. Standards for Reporting Qualitative Research: A Synthesis of Recommendations. Academic Medicine. 2014;89(9):1245-1251.

18. Connell LA KT, Janssen J, Thetford C, Eng JJ. Delivering intensive rehabilitation in stroke: factors influencing implementation. Physical Therapy. 2018;98(4):243-250.

19. Connell LA MN, Harris JE, Watkins CL, Eng JJ. A formative evaluation of the implementation of an upper limb stroke rehabilitation intervention in clinical practice: a qualitative interview study. Implementation Science. 2014;9:90.

20. Pellerin MA, Lamontagne ME, Viau-Guay A, Poulin V. Systematic review of determinants influencing knowledge implementation in occupational therapy. Aust Occup Ther J. Oct 8 2019; doi:10.1111/1440-1630.12612

21. McCluskey A V-CA, Schurr K. Barriers and enablers to implementing multiple stroke guideline recommendations: a qualitative study. BMC Health Services Research. 2013;13:323.

22. Van Kessel G HS, English C. Physiotherapists' attitudes toward circuit class therapy and 7 day per week therapy is influenced by normative beliefs, past experience, and perceived control: A qualitative study. Physiotherapy Theory and Practice. 2017;33(11):850858.

23. Perry CK DL, Hemler JR, Woodson TT, Ono SS, Cohen DJ. Specifying and comparing implementation strategies across seven large implementation interventions: a practical application of theory. Implementation Science. 2019;14:32.

24. Rogal SS YV, Waltz TJ, Powell BJ, Kirchner JE, Proctor EK, Gonzalez R, Park A, Ross D, Morgan TR, Chartier M, Chinman MJ. The association between implementation strategy use and the uptake of hepatitis $\mathrm{C}$ treatment in a national sample. Implementation Science. 2017;12:60.

25. Powell BJ BR, Lewis CC, Aarons GA, McMillen JC, Proctor EK, Mandell DS. Methods to improve the selection and tailoring of implementation strategies. The Journal of Behavioral Health Services and Research. 2017;44(2):177-194.

26. Bartholomew Eldredge LK MC, Ruiter RAC, Fernández ME, Kok G, Parcel GS. Planning health promotion programs: an intervention mapping approach. 4 th ed. JosseyBass; 2016.

27. Carey RN CL, Johnston M, Rothman AJ, de Bruin M, Kelly MP, Michie S. Behaviour change techniques and their mechanisms of action: a synthesis of links described in published intervention literature. Annals of Behavioral Medicine. 2019;53(8):693-707.

28. Clarke DJ GM, Hawkins R, Sadler E, Harding G, Forster A, McKevitt C, Dickerson J, Farrin A. Implementing a training intervention to support caregivers after stroke: a process evaluation examining the initiation and embedding of programme change. Implementation Science. 2013;8:96.

29. Greenhalgh T WJ, Papoutsi C, Lynch J, Hughes G, A'Court C, Hinder S, Procter R, Shaw S. Analysing the role of complexity in explaining the fortunes of technology programmes: empirical application of the NASSS framework. BMC Medicine. 2018;16:66. 30. Waltz TJ PB, Fernández ME, Abadie B, Damschroder LJ. Choosing implementation strategies to address contextual barriers: diversity in recommendations and future directions. Implementation Science. 2019;14(1):42. 
31. Wolff RF, Moons KGM, Riley RD, et al. PROBAST: A Tool to Assess the Risk of Bias and Applicability of Prediction Model Studies. Ann Intern Med. 01 2019;170(1):51-58. doi:10.7326/M18-1376

32. Boyd MR PB, Endicott D, Lewis CC. A method for tracking implementation strategies: an exemplar implementing measurement-based care in community behavioral health clinics. Behavior Therapy. 2018;49(4):525-537.

33. PREP2 Training. University of Auckland. https://preptraining.auckland.ac.nz/ 34. PRESTO. Predict stroke outcomes. University of Auckland.

https://presto.auckland.ac.nz/ 
Table 1: Implementation strategies used and lessons for future implementation efforts.

\begin{tabular}{|c|c|c|c|}
\hline & $\begin{array}{l}\text { Relevant ERIC } \\
\text { strategies }\end{array}$ & $\begin{array}{l}\text { What worked well } \\
\text { at Auckland District } \\
\text { Health Board }\end{array}$ & $\begin{array}{l}\text { Lessons for future } \\
\text { implementation efforts }\end{array}$ \\
\hline \multicolumn{4}{|c|}{ IMPLEMENTATION TEAM } \\
\hline $\begin{array}{l}\text { Development of } \\
\text { the PREP2 } \\
\text { implementation } \\
\text { group }\end{array}$ & $\begin{array}{l}\text { - } \text { Assess for } \\
\text { readiness and } \\
\text { identify barriers } \\
\text { and facilitators } \\
\text { - Identify and } \\
\text { prepare } \\
\text { champions } \\
\text { - Obtain formal } \\
\text { commitments } \\
\text { - Organise } \\
\text { clinician } \\
\text { implementation } \\
\text { team meetings } \\
\text { - Develop and } \\
\text { organize quality } \\
\text { monitoring } \\
\text { - } \text { systems } \\
\text { Provide clinical } \\
\text { - Rupervision } \\
\text { - Pemind clinicians } \\
\text { Provide local } \\
\text { technical } \\
\text { assistance }\end{array}$ & $\begin{array}{l}\text { PREP2 'leaders', who } \\
\text { were key in } \\
\text { championing and } \\
\text { promoting PREP2, } \\
\text { emerged and evolved } \\
\text { informally over time. } \\
\text { Eventually a formal } \\
\text { role was allocated for } \\
\text { a 'PREP2 lead } \\
\text { therapist'. } \\
\text { Implementation was } \\
\text { led by the Physical } \\
\text { Therapists. } \\
\text { Occupational } \\
\text { Therapists were keen } \\
\text { to be involved and } \\
\text { were involved later in } \\
\text { the implementation } \\
\text { process. } \\
\text { Members of the } \\
\text { PREP2 } \\
\text { implementation group } \\
\text { were often present on } \\
\text { the ward. They } \\
\text { trained staff, and } \\
\text { were useful as a } \\
\text { resource for specific } \\
\text { cases and queries. }\end{array}$ & $\begin{array}{l}\checkmark \text { Nominate and support } \\
\text { formal PREP2 } \\
\text { Champions to lead } \\
\text { implementation. } \\
\text { Allocate these as } \\
\text { formal roles (if } \\
\text { possible). } \\
\\
\text { Include a variety of } \\
\text { Health Care } \\
\text { Professionals (most } \\
\text { importantly Physical } \\
\text { Therapists and } \\
\text { Occupational } \\
\text { Therapists) in the } \\
\text { implementation team. } \\
\checkmark \text { From the outset plan } \\
\text { for sustainability in } \\
\text { terms of training } \\
\text { enough staff for the } \\
\text { different parts of the } \\
\text { PREP2 pathway. } \\
\checkmark \text { Ensure that members } \\
\text { of the implementation } \\
\text { team are often present } \\
\text { within the clinical } \\
\text { setting. } \\
\checkmark \text { Use a phased approach } \\
\text { to implementation, e.g. } \\
\text { train clinicians in use of } \\
\text { the SAFE score first and } \\
\text { delivering Excellent } \\
\text { and Good predictions, } \\
\text { before moving onto } \\
\text { training in the use of } \\
\text { the TMS and NIHSS and } \\
\text { delivering Limited and } \\
\text { Poor predictions. }\end{array}$ \\
\hline
\end{tabular}




\begin{tabular}{|c|c|c|c|}
\hline $\begin{array}{l}\text { Implementation } \\
\text { activities }\end{array}$ & $\begin{array}{l}\text { - } \text { Facilitation } \\
\text { - Promote } \\
\text { - } \text { Capaptability } \\
\text { - } \text { local knowledge } \\
\text { - Tailor strategies } \\
\text { - Conduct cyclical } \\
\text { small tests of } \\
\text { change } \\
\text { - Audit and } \\
\text { provide } \\
\text { feedback }\end{array}$ & $\begin{array}{l}\text { The support from } \\
\text { management was } \\
\text { beneficial. } \\
\text { Clinicians worked with } \\
\text { the implementation } \\
\text { team to get feedback } \\
\text { on their practice and } \\
\text { continually drive } \\
\text { improvement. } \\
\text { Audit and feedback of } \\
\text { PREP2 practice were } \\
\text { undertaken. }\end{array}$ & $\begin{array}{l}\checkmark \text { Obtain management } \\
\text { staff approval and } \\
\text { encourage their } \\
\text { support and promotion } \\
\text { of PREP2. } \\
\checkmark \text { Work with the wider } \\
\text { Multi-Disciplinary } \\
\text { Team to explore how } \\
\text { PREP2 can be tailored } \\
\text { to different patient } \\
\text { needs, e.g. discuss } \\
\text { communication } \\
\text { strategies with speech } \\
\text { language therapists } \\
\checkmark \text { Encourage working } \\
\text { relations between } \\
\text { clinicians and the } \\
\text { implementation team } \\
\text { that promote honest } \\
\text { discussions about } \\
\text { practice and strive for } \\
\text { continual } \\
\text { improvement. } \\
\checkmark \text { Undertake audits of } \\
\text { practice; identify } \\
\text { changes needed; } \\
\text { action these changes, } \\
\text { and then re-audit. }\end{array}$ \\
\hline \multicolumn{4}{|c|}{ CLINICAL ACADEMIC PARTNERSHIPS } \\
\hline $\begin{array}{l}\text { Developing strong } \\
\text { clinical/academic } \\
\text { relations }\end{array}$ & $\begin{array}{l}\text { - } \text { Create a learning } \\
\text { collaborative } \\
\text { - } \text { Build a coalition } \\
\text { - } \text { Develop } \\
\text { academic } \\
\text { partnerships } \\
\text { - Work with } \\
\text { educational } \\
\text { institutions }\end{array}$ & $\begin{array}{l}\text { There were close links } \\
\text { between the PREP2 } \\
\text { research team, the } \\
\text { implementation team } \\
\text { and the clinicians. This } \\
\text { was partly achieved } \\
\text { by split clinical- } \\
\text { academic roles. } \\
\text { Clinicians found it } \\
\text { helpful to be shown } \\
\text { the evidence that } \\
\text { underpins PREP2. }\end{array}$ & $\begin{array}{l}\text { Try to establish close } \\
\text { links between clinicians } \\
\text { and academics. Sites } \\
\text { could explore the local } \\
\text { academic resources } \\
\text { available to them, or } \\
\text { connect with the } \\
\text { PREP2 team in } \\
\text { Auckland via the PREP } \\
\text { Training website. }{ }^{33} \\
\\
\text { Re-use existing } \\
\text { resources to } \\
\text { demonstrate the } \\
\text { evidence underpinning } \\
\text { PREP2, for example } \\
\text { using the PREP2 } \\
\text { websites. }{ }^{33,34}\end{array}$ \\
\hline
\end{tabular}




\begin{tabular}{|c|c|c|c|}
\hline \multicolumn{4}{|c|}{ TRAINING } \\
\hline $\begin{array}{l}\text { Delivery of } \\
\text { training }\end{array}$ & $\begin{array}{ll}\text { - } & \begin{array}{l}\text { Conduct } \\
\text { ongoing } \\
\text { training }\end{array} \\
\text { - } & \text { Make } \\
\text { training } \\
\text { dynamic } \\
\text { - Use "train } \\
\text { the trainer" } \\
\text { strategies } \\
\text { - Develop } \\
\text { educational } \\
\text { materials } \\
\text { Distribute } \\
\text { educational } \\
\text { materials }\end{array}$ & $\begin{array}{l}\text { Overall, staff found } \\
\text { training useful. } \\
\text { Training formats } \\
\text { included group } \\
\text { workshops, one-to- } \\
\text { one teaching and self- } \\
\text { directed online } \\
\text { learning. }{ }^{33} \text { A folder } \\
\text { containing } \\
\text { information about } \\
\text { PREP2 was created as } \\
\text { a useful resource for } \\
\text { clinicians. } \\
\text { Senior clinicians were } \\
\text { trained to be able to } \\
\text { support more junior } \\
\text { staff in the delivery of } \\
\text { PREP2. }\end{array}$ & 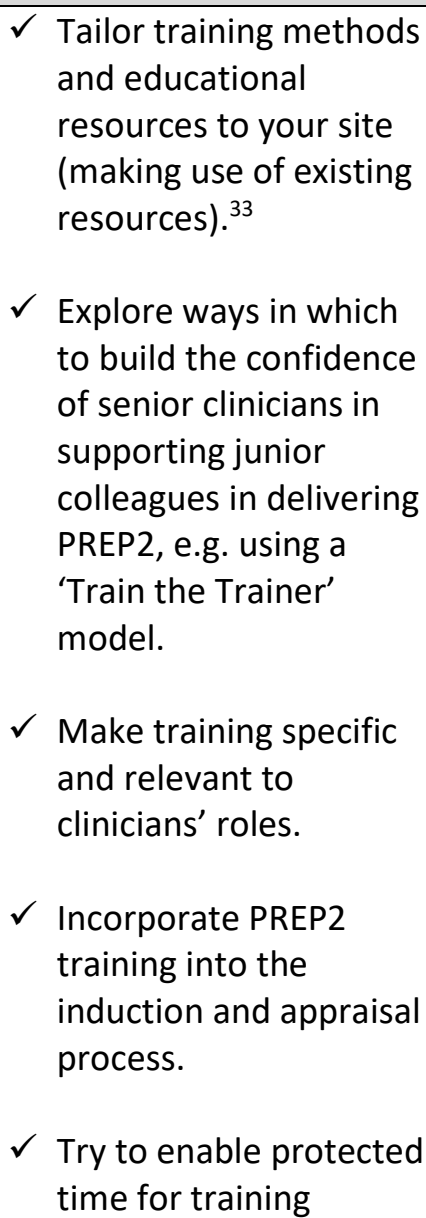 \\
\hline $\begin{array}{l}\text { Providing support } \\
\text { to clinicians }\end{array}$ & 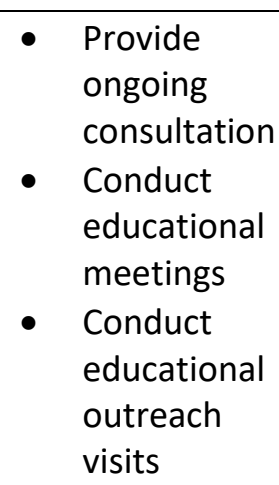 & $\begin{array}{l}\text { The implementation } \\
\text { team delivered formal } \\
\text { and informal training, } \\
\text { and one-to-one } \\
\text { coaching was also } \\
\text { available. They made } \\
\text { themselves available } \\
\text { for advice and queries } \\
\text { from staff on the } \\
\text { wards. }\end{array}$ & $\begin{array}{l}\checkmark \text { Consider ways in which } \\
\text { the implementation } \\
\text { team support the } \\
\text { clinical staff, including } \\
\text { both formal and } \\
\text { informal methods, with } \\
\text { both group training } \\
\text { and one-to-one } \\
\text { sessions. }\end{array}$ \\
\hline
\end{tabular}


Table 2. Factors Influencing Implementation of PREP2

\begin{tabular}{|c|c|}
\hline \multicolumn{2}{|r|}{ Consolidated Framework for Implementation Research (CFIR) } \\
\hline \multicolumn{2}{|r|}{ Inner Setting } \\
\hline Culture & $\begin{array}{l}\text { PREP } 2 \text { is embedded within the normal care for stroke survivors, with training for new staff part of standard } \\
\text { orientation. }\end{array}$ \\
\hline $\begin{array}{l}\text { Readiness for } \\
\text { Implementation }\end{array}$ & Leadership engagement recognized as important, but implementation was led by therapists. \\
\hline Structural Characteristics & $\begin{array}{l}\text { Different wards (acute/rehabilitation) and different staff are required for obtaining predictions, which has } \\
\text { implications for logistics and staffing. }\end{array}$ \\
\hline $\begin{array}{l}\text { Networks and } \\
\text { Communication }\end{array}$ & $\begin{array}{l}\text { Communication is important to enable the tests to be completed on time, and to ensure consistent language } \\
\text { when sharing PREP2 information with clinicians and patients (and their families). } \\
\text { Communication between staff was generally good within a service, but more challenging with other services. }\end{array}$ \\
\hline Implementation climate & $\begin{array}{l}\text { Staff are generally supportive towards training and staff development. } \\
\text { Lack of a systematic feedback loop meant there was no insight into the outcome of predictions. }\end{array}$ \\
\hline \multicolumn{2}{|r|}{ Characteristics of Individuals } \\
\hline Knowledge and Beliefs & $\begin{array}{l}\text { Mostly positive perceptions regarding PREP2 as a tool for predicting upper limb functional outcome for } \\
\text { individual patients. }\end{array}$ \\
\hline Self-Efficacy & $\begin{array}{l}\text { Recognition that people are trained on the parts of PREP2 that were relevant to them. } \\
\text { Therapists had varied confidence levels in their abilities to perform the different aspects of PREP } 2 \text { and took time } \\
\text { to build confidence. }\end{array}$ \\
\hline Other Personal Attributes & $\begin{array}{l}\text { Passionate PREP2 champions and knowledgeable therapists gave the wider team support and confidence. } \\
\text { Therapists appreciated the opportunity to be involved in 'ground-breaking practice' and to learn new skills that } \\
\text { advance PT and OT professions. }\end{array}$ \\
\hline \multicolumn{2}{|r|}{ Intervention Characteristics } \\
\hline Complexity & $\begin{array}{l}\text { PREP2 algorithm includes relatively 'simple' biomarkers but is still complex to implement in a clinical setting. } \\
\text { Sustainability and staff turn-over need to be considered from the outset. } \\
\text { Time needed for training and undertaking PREP2 assessments can be a challenge. } \\
\text { Some difficulties posed when a prediction isn't borne out in an expected time-frame. }\end{array}$ \\
\hline
\end{tabular}




\begin{tabular}{|l|l|}
\hline $\begin{array}{l}\text { Evidence Strength and } \\
\text { Quality }\end{array}$ & Having evidence to support PREP2 helped clinicians believe in its accuracy and usefulness. \\
\hline Relative Advantage & $\begin{array}{l}\text { PREP2 predictions helped guide and focus UL rehabilitation. } \\
\text { Receiving a prognosis is felt to help patients with acceptance. } \\
\text { Unintended consequence of helping detect deterioration. }\end{array}$ \\
\hline $\begin{array}{l}\text { Patient Needs and } \\
\text { Resources }\end{array}$ & $\begin{array}{l}\text { Patients and their families varied in terms of whether they wanted to know their prediction. } \\
\text { Knowing their prediction may impact on the patient's mood and motivation, either positively or negatively. }\end{array}$ \\
\hline
\end{tabular}




\section{Appendix 1. Interview guide for study}

\begin{tabular}{|c|c|}
\hline \multicolumn{2}{|c|}{$\begin{array}{l}\text { INTRODUCTORY QUESTIONS } \\
\end{array}$} \\
\hline \multicolumn{2}{|c|}{$\begin{array}{l}\text { - Can you describe your role in stroke rehabilitation? } \\
\text { - For how long have you been working specifically in stroke rehabilitation? } \\
\text { - Is this your first time being involved in research? }\end{array}$} \\
\hline \multicolumn{2}{|r|}{ PREP2 } \\
\hline \multicolumn{2}{|c|}{$\begin{array}{l}\text { - How did you hear about the PREP2? } \\
\text { - Can you describe in your own words what the PREP2 is? (ask about both obtaining } \\
\text { the information and using the predictions) } \\
\text { - Can you describe in your own words how the PREP2 is incorporated in to your } \\
\text { work? }\end{array}$} \\
\hline \multicolumn{2}{|r|}{ CHARACTERISTICS OF INDIVIDUAL } \\
\hline \multicolumn{2}{|c|}{$\begin{array}{l}\text { - What is your opinion on the concept of predictive algorithms/ PREP2 for people } \\
\text { with stroke? } \\
\text { - Had you any concerns about getting the right information on prognosis? } \\
\text { - Had you any concerns about giving out the prediction information? } \\
\text { - Do you think that PREP2 will is helpful your clinical setting? } \\
\text { - How confident are you in using PREP2? } \\
\text { - How confident do you think your colleagues feel about using PREP2? }\end{array}$} \\
\hline \multicolumn{2}{|r|}{ COHERENCE } \\
\hline $\begin{array}{l}\text { Differentiation } \\
\text { (Is PREP2 perceived to } \\
\text { be different from } \\
\text { traditional ways of } \\
\text { working?) }\end{array}$ & $\begin{array}{l}\text { Does using PREP2 mean you do anything different from what } \\
\text { you used to do on a daily basis anyway? If yes, how is it } \\
\text { different? }\end{array}$ \\
\hline $\begin{array}{l}\text { Communal } \\
\text { Specification } \\
\text { (Does everybody } \\
\text { understand PREP2?) }\end{array}$ & $\begin{array}{l}\text { Do you think the purpose of the PREP } 2 \text { is clearly conveyed in } \\
\text { the resources provided? } \\
\text { Was the training sufficient? }\end{array}$ \\
\hline $\begin{array}{l}\text { Individual } \\
\text { Specification } \\
\text { (Does everybody } \\
\text { understand what they } \\
\text { have to do when using } \\
\text { PREP2?) }\end{array}$ & $\begin{array}{l}\text { Does using PREP2 fit into your role in inpatient rehabilitation? } \\
\text { Do the patients understand what they have to do when } \\
\text { undertaking the tests for the PREP2 (SAFE/ NIHSS/ TMS)? } \\
\text { Do you think patients understand the predictions? }\end{array}$ \\
\hline $\begin{array}{l}\text { Internalisation } \\
\text { (Does everybody think } \\
\text { it is worth the effort?) }\end{array}$ & $\begin{array}{l}\text { Do the people you work with like PREP2? } \\
\text { Do you think patients think PREP2 is worth the effort? }\end{array}$ \\
\hline \multicolumn{2}{|r|}{ COGNITIVE PARTICIPATION } \\
\hline $\begin{array}{l}\text { Initiation } \\
\text { (Are there key } \\
\text { individuals that } \\
\text { advocate for PREP2?) }\end{array}$ & $\begin{array}{l}\text { Was there enough direction in getting going at the start? Did } \\
\text { your manager support you being involved in the } \\
\text { implementation? }\end{array}$ \\
\hline Enrolment & Are other colleagues now using PREP2 regularly? \\
\hline
\end{tabular}




\begin{tabular}{|c|c|}
\hline $\begin{array}{l}\text { (Have people "bought } \\
\text { into" PREP2?) }\end{array}$ & \\
\hline $\begin{array}{l}\text { Legitimation } \\
\text { (Are the right people } \\
\text { doing the right tasks?) }\end{array}$ & Does anything get in the way of implementing PREP2? \\
\hline $\begin{array}{l}\text { Activation } \\
\text { (Is everybody ready to } \\
\text { make an action plan?) }\end{array}$ & $\begin{array}{l}\text { What has helped in implementing PREP2? } \\
\text { Has using PREP2 affected how your work is organised? }\end{array}$ \\
\hline & COLLECTIVE ACTION \\
\hline $\begin{array}{l}\text { Interactional } \\
\text { Workability } \\
\text { (Is the work involved in } \\
\text { delivering PREP2 } \\
\text { appropriately } \\
\text { allocated?) }\end{array}$ & Have there been any problems implementing PREP2? \\
\hline $\begin{array}{l}\text { Relational Integration } \\
\text { (Do staff trust each } \\
\text { other's work and } \\
\text { expertise in using the } \\
\text { PREP2?) }\end{array}$ & $\begin{array}{l}\text { Are people confident that PREP2 can be implemented as it } \\
\text { should be? }\end{array}$ \\
\hline $\begin{array}{l}\text { Skill Set Workability } \\
\text { (Can people perform } \\
\text { the tasks that are being } \\
\text { asked of them?) }\end{array}$ & $\begin{array}{l}\text { Do people have the right skills and knowledge needed to } \\
\text { implement PREP2? (ask about both obtaining the information } \\
\text { and using the predictions) } \\
\text { Has there been any training provided? }\end{array}$ \\
\hline $\begin{array}{l}\text { Contextual Integration } \\
\text { (Is PREP } 2 \text { adequately } \\
\text { supported by the host } \\
\text { organisation?) }\end{array}$ & $\begin{array}{l}\text { Is there sufficient support from your works setting for } \\
\text { implementing PREP2? } \\
\text { Is there anything in particular that supported the } \\
\text { implementation of PREP2? }\end{array}$ \\
\hline & REFLEXIVE MONITORING \\
\hline $\begin{array}{l}\text { Systematizing } \\
\text { (Is implementing PREP2 } \\
\text { worthwhile?) }\end{array}$ & How do you measure if PREP2 is worthwhile or not? \\
\hline $\begin{array}{l}\text { Communal Appraisal } \\
\text { (Are people finding } \\
\text { implementing PREP2 a } \\
\text { worthwhile venture?) }\end{array}$ & Do people generally think it is worth continuing to use PREP2? \\
\hline $\begin{array}{l}\text { Individual Appraisal } \\
\text { (Do individuals } \\
\text { evaluate the new } \\
\text { practice as } \\
\text { worthwhile?) }\end{array}$ & $\begin{array}{l}\text { Will you continue to use PREP } 2 \text { in practice? What factors would } \\
\text { influence this decision? }\end{array}$ \\
\hline $\begin{array}{l}\text { Reconfiguration } \\
\text { (Do people modify their } \\
\text { practice in response to } \\
\text { evaluations made?) }\end{array}$ & $\begin{array}{l}\text { Is PREP2 easy to implement? } \\
\text { Do you do anything differently after having experience of using } \\
\text { PREP2? Any lessons learned we can pass on to others? }\end{array}$ \\
\hline
\end{tabular}

